\title{
Targeted inhibition of mitochondrial Hsp90 suppresses localised and metastatic prostate cancer growth in a genetic mouse model of disease
}

\author{
BH Kang ',6, M Tavecchio ${ }^{1,2}$, HL Goel ${ }^{1,3}$, C-C Hsieh ${ }^{1,3}$, DS Garlick ${ }^{1,3}$, CM Raskett ${ }^{1,3}$, JB Lian ${ }^{1,4}$, GS Stein ${ }^{1,4}$, \\ LR Languino ${ }^{1,5}$ and DC Altieri*,1,2
}

'Prostate Cancer Discovery and Development Program, 3601 Spruce Street, Philadelphia, PA 19104, USA; ${ }^{2}$ Wistar Institute Cancer Center, 3601 Spruce Street, Philadelphia, PA 19104, USA; ${ }^{3}$ Department of Cancer Biology, University of Massachusetts Medical School, Worcester, MA 0I 605, USA;

${ }^{4}$ Department of Cell Biology, University of Massachusetts Medical School, Worcester, MA 0 I605, USA; ${ }^{5}$ Department of Cancer Biology, Kimmel Cancer Center, Thomas Jefferson University, Philadelphia, PA 19107, USA

\begin{abstract}
BACKGROUND: The molecular chaperone heat shock protein-90 (Hsp90) is a promising cancer drug target, but current Hsp90-based therapy has so far shown limited activity in the clinic.

METHODS: We tested the efficacy of a novel mitochondrial-targeted, small-molecule Hsp90 inhibitor, Gamitrinib (GA mitochondrial matrix inhibitor), in the Transgenic Adenocarcinoma of the Mouse Prostate (TRAMP) model. The TRAMP mice receiving 3-week or 5-week systemic treatment with Gamitrinib were evaluated for localised or metastatic prostate cancer, prostatic intraepithelial neoplasia (PIN) or localised inflammation using magnetic resonance imaging, histology and immunohistochemistry. Treatment safety was assessed histologically in organs collected at the end of treatment. The effect of Gamitrinib on mitochondrial dysfunction was studied in RMI cells isolated from TRAMP tumours.

RESULTS: Systemic administration of Gamitrinib to TRAMP mice inhibited the formation of localised prostate tumours of neuroendocrine or adenocarcinoma origin, as well as metastatic prostate cancer to abdominal lymph nodes and liver. The Gamitrinib treatment had no effect on PIN or prostatic inflammation, and caused no significant animal weight loss or organ toxicity. Mechanistically, Gamitrinib triggered acute mitochondrial dysfunction in RMI cells, with loss of organelle inner membrane potential and release of cytochrome-c in the cytosol.

CONCLUSIONS: The Gamitrinib has pre-clinical activity and favourable tolerability in a genetic model of localised and metastatic prostate cancer in immunocompetent mice. Selective targeting of mitochondrial Hsp90 could provide novel molecular therapy for patients with advanced prostate cancer.
\end{abstract}

British Journal of Cancer (201 I) 1 04, 629-634. doi:10.1038/bjc.2011.9 www.bjcancer.com

Published online I February 201 I

(c) 20II Cancer Research UK

Keywords: prostate cancer; metastasis; mitochondria; Hsp90; TRAMP

Despite advances in treating early-phase prostate cancer (Carter et al, 2006), advanced disease, characterised by castration resistance and bone metastases, poses significant therapeutic challenges (Taichman et al, 2007), with over 30000 deaths in the United States alone. Cytotoxic or radiation has limited efficacy in these patients, and molecular therapies are still in early stages of evaluation (Vogiatzi et al, 2009). Because advanced prostate cancer is heterogeneous (Taylor et al, 2010), targeting so-called 'nodal' cancer genes (Lamb et al, 2006) overseeing multiple downstream pathways of tumour maintenance (Butcher, 2005) may offer concrete therapeutic prospects. In this context, the molecular chaperone heat shock protein-90 (Hsp90) is a nodal cancer gene

\footnotetext{
*Correspondence: Dr DC Altieri; E-mail: daltieri@wistar.org

${ }^{6}$ Present address: School of Nano-Biotechnology and Chemical Engineering, Ulsan National Institute of Science and Technology, I00 Banyeon-ri, Ulsan, 689-798 South Korea.

Revised 22 December 20 I0; accepted 5 January 20 I I; published online I February 2011
}

(Whitesell and Lindquist, 2005), controlling the folding and/or maturation of client proteins involved in tumour cell proliferation, survival and adaptation (Trepel et al, 2010). The Hsp90 has been intensely pursued for cancer therapeutics, and several small-molecule antagonists of its ATPase pocket have been developed (Drysdale and Brough, 2008). However, Hsp90-based therapy (Kim et al, 2009) has shown so far modest activity in patients with epithelial malignancies, including prostate cancer (Heath et al, 2008), whether as single agent (Solit et al, 2008) or combined with cytotoxics (Tse et al, 2008) or molecular therapies (Modi et al, 2007).

A key feature of Hsp90 and Hsp90-like molecules is their localisation to multiple subcellular compartments (Trepel et al, 2010). Recently, a pool of Hsp90 has been found in mitochondria of tumour cells (Kang et al, 2007), where it promotes cell survival by antagonising cyclophilin $\mathrm{D}(\mathrm{CypD})$-dependent organelle permeability transition and apoptosis (Green and Kroemer, 2004). Whether this pathway (Kang et al, 2007) influences the response to Hsp90-based therapy in the clinic (Trepel et al, 2010) is 
currently unknown, but it is intriguing that none of the Hsp90 ATPase antagonists currently in (pre)clinical development (Drysdale and Brough, 2008) has the ability to accumulate in mitochondria (Kang et al, 2009), thus leaving unscathed this general survival mechanism. To address this limitation, a new class of small-molecule Hsp90 inhibitors selectively targeted to mitochondria, that is, Gamitrinibs (GA mitochondrial matrix inhibitors) was recently generated (Kang et al, 2009), which exhibited potent anti-cancer activity in various xenograft tumour models, in vivo (Kang et al, 2009).

In this study, we evaluated the pre-clinical activity of Gamitrinib in the Transgenic Adenocarcinoma of the Mouse Prostate (TRAMP) model (Greenberg et al, 1995). Albeit with limitations (Pienta et al, 2008), prostatic tumourigenesis in TRAMP mice recapitulates many aspects of the human disease on an immunocompetent background (Kaplan-Lefko et al, 2003), and is suitable for cancer drug discovery, in vivo (Zorn et al, 2007).

\section{MATERIALS AND METHODS}

\section{Cells and reagents}

RM1 cells derived from TRAMP mice have been described (Voeks et al, 2002). The chemical synthesis, HPLC profile and mass spectrometry of mitochondria-targeted small-molecule Hsp90 antagonists, Gamitrinibs, have been reported (Kang et al, 2009). This study utilised Gamitrinib-G4 (G-G4), which contains the Hsp90 ATPase inhibitory structure of 17-AAG (LC-Laboratories, Woburn, MA, USA) linked to four tandem repeats of guanidinium, used as a mitochondriotropic moiety (Kang et al, 2009).

\section{The Gamitrinib treatment of TRAMP mice}

All experiments involving animals were approved by an Institutional Animal Care and Use Committee. The TRAMP model has been described (Kaplan-Lefko et al, 2003), and involves expression of the SV40 large T and small $t$ oncogene in the prostatic epithelium under the control of the minimal $-426 /+28$ rat probasin promoter (Greenberg et al, 1995). Transgene expression is regulated by androgen, and results in a spectrum of lesions, including prostatic intraepithelial neoplasia (PIN), invasive adenocarcinoma, neuroendocrine tumours and metastases to loco-regional abdominal lymph nodes, liver and lungs (Greenberg et al, 1995; Kaplan-Lefko et al, 2003). Female TRAMP mice on a C57BL/6 background were bred with non-transgenic males, and the offspring was weaned at 3-4 weeks of age. Male pups were genotyped by PCR amplification of tail genomic DNA using transgene-specific primers. To test a potential anticancer activity of Gamitrinib (Kang et al, 2009) in this model, TRAMP mice were divided into two age groups to receive $\mathrm{G}-\mathrm{G} 4$ monotherapy at $5 \mathrm{mg} / \mathrm{kg}$ in cremophor as i.p. injections, with the schedule 3 days on $/ 2$ days off. Mice in group 1 (short-term treatment) received G-G4 starting at 21.9 weeks of age for 3 weeks (24.9 weeks of age), with analysis of primary and metastatic prostate cancer as end point. Animals in group 2 (long-term treatment) were started on G-G4 at 14.7 weeks of age for 5 weeks (19.7 weeks of age) and assessed histologically for primary prostate cancer growth, PIN and localised inflammation.

\section{Magnetic resonance imaging}

The $2 \mathrm{~T}$ magnetic resonance imaging (MRI) analysis of TRAMP mice was carried out on a Bruker/General Electric CSI-II 2.0 $\mathrm{T} / 45 \mathrm{~cm}$ imaging spectrometer (Madison, WI, USA) equipped with a thermostat-controlled animal holder and gas anaesthesia, containing magnetic field gradients, RF phase, amplitude control and automatic shimming. For these experiments, 20-week-old non-castrated TRAMP mice were imaged by MRI using the following parameters: repetition time $(T R)=2000 / 600 \mathrm{~ms}$; echo time $(\mathrm{TE})=25 \mathrm{~ms}$; data acquisition field-of-view $=40 \mathrm{~mm} \times$ $40 \mathrm{~mm} / 30 \mathrm{~mm} \times 30 \mathrm{~mm}$; slice thickness $(\mathrm{ST})=1 \mathrm{~mm}$; data acquisition matrix $=256 \times 256$; number of echo averages $=4$; and display $\mathrm{FO}=30 \mathrm{~mm} \times 30 \mathrm{~mm}$.

\section{Analysis of mitochondrial dysfunction}

RM1 cells isolated from TRAMP prostate tumours (Voeks et al, 2002) were incubated with $20 \mu \mathrm{M} \mathrm{G}-\mathrm{G} 4$ or non-mitochondrially targeted Hsp90 inhibitor, 17-AAG, and analysed after $12 \mathrm{~h}$ for changes in mitochondrial membrane potential by JC-1 $(200 \mu \mathrm{M})$ staining and multiparametric flow cytometry on a FACSCalibur (Becton Dickinson, Franklin Lake, NJ, USA), as described (Kang et al, 2009). Alternatively, cytosolic extracts were isolated from treated RM1 cells using an ApoAlert Cell Fractionation Kit (Clontech, Otsu, Shiga, Japan), and analysed by western blotting.

\section{Histology}

The TRAMP mice in control or G-G4-treated groups were killed, and the entire genitourinary tract containing seminal vesicles, prostate (including dorsal, lateral, ventral and anterior lobes) and urethra (thus excluding the urinary bladder), was isolated, fixed and stained with hematoxylin/eosin. In some experiments, tissue sections were stained with an antibody to the proliferationassociated marker, Ki67, as described (Kang et al, 2009). At the end of the experiment, organs from control or G-G4-treated TRAMP mice were removed, paraffin embedded and analysed by $\mathrm{H} \& \mathrm{E}$ staining and light microscopy. The histological analysis in each case was performed by a veterinary pathologist (DSG), and the percentage of prostate gland involvement with PIN, adenocarcinoma or neuroendocrine tumours was assessed in individual prostatic lobes. The scoring system used to quantify inflammation or metastatic prostate cancer was as follows: 0 , none; 1 , mild; 2 , moderate; and 3, marked.

\section{Statistical analysis}

Data were analysed using the unpaired $t$-test on a GraphPad software package (Prism 4.0, La Jolla, CA, USA) for Windows. All statistical tests were two sided. A $P$-value of 0.05 was considered to be statistically significant.

\section{RESULTS}

\section{Prostate tumourigenesis in TRAMP mice}

We began this study by quantifying prostate cancer growth in untreated TRAMP mice (Greenberg et al, 1995). Consistent with previous reports (Kaplan-Lefko et al, 2003), TRAMP mice at 22 weeks of age exhibited enlarged prostates, by MRI (Supplementary Figure 1). Prostatic lesions under these conditions included well-differentiated adenocarcinomas with low proliferative index as well as large neuroendocrine tumours, composed of sheets of small, undifferentiated cells that stained intensely for the proliferation-associated marker, Ki-67 (Supplementary Figure 1).

\section{Gamitrinib inhibits localised prostate cancer growth in TRAMP mice}

Consistent with these data, prostatic samples from untreated TRAMP mice harvested at 19.7 weeks of age (group 2) revealed the presence of neuroendocrine tumours, adenocarcinomas and PIN lesions, mixed with various degrees of local inflammation (Figure 1). Large neuroendocrine tumours occupying $>50 \%$ of a prostatic lobe were observed in dorso-lateral and ventral prostate samples (Figure $1 \mathrm{~A}$ and $\mathrm{B}$ ), whereas adenocarcinomas 

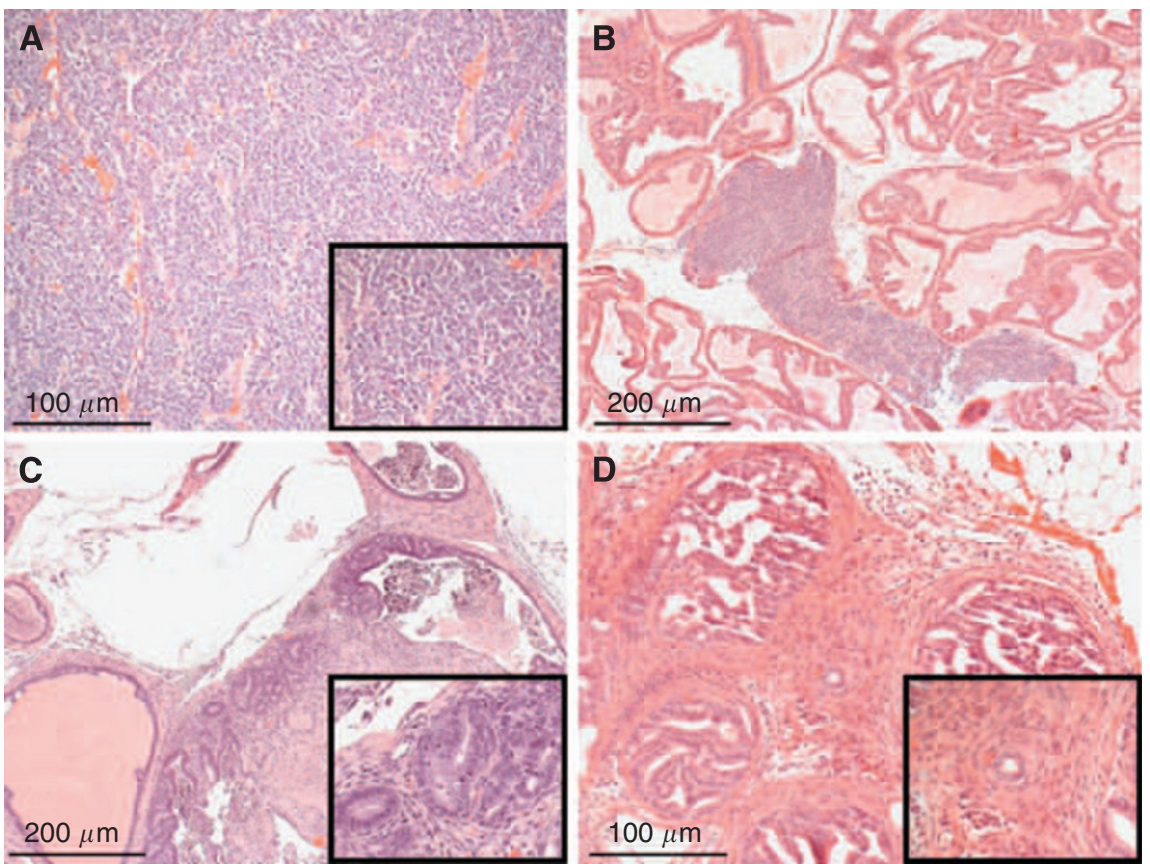

Figure I Prostate histopathology of untreated TRAMP mice at 19.7 weeks of age (group 2). Prostatic samples were isolated from group 2 TRAMP mice, and analysed by H\&E staining and light microscopy. Representative cases of prostatic neuroendocrine tumours (A, B; ventral prostate) or adenocarcinoma (C, D; dorsal prostate) in group 2 TRAMP mice associated with extensive PIN lesions and various degrees of inflammation are shown.

Table I Prostate histopathology in untreated TRAMP mice age matched to group 2 (19.7 weeks)

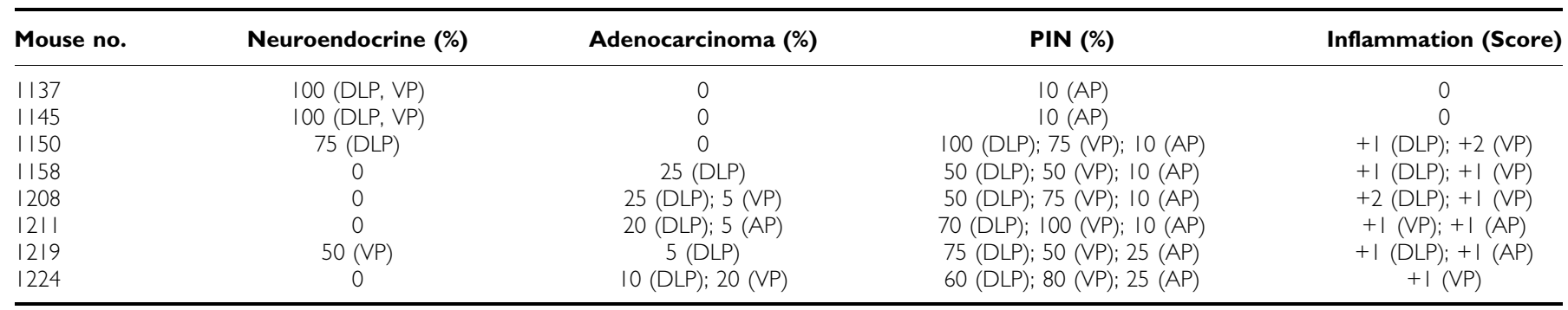

Abbreviations: $\mathrm{AP}=$ anterior prostate; $\mathrm{DLP}=$ dorso-lateral prostate; $\mathrm{PIN}=$ prostatic intraepithelial neoplasia; TRAMP $=$ Transgenic Adenocarcinoma of the Mouse Prostate; $\mathrm{VP}=$ ventral prostate

(Figure 1C and D) were histologically well differentiated, of smaller size, that is, $5-25 \%$ of a prostatic lobe and equally distributed in dorso-lateral, ventral and anterior prostate. A complete histopathological analysis of control group 2 TRAMP mice is presented in Table 1.

Long-term treatment of group 2 TRAMP mice with G-G4 suppressed the growth of localised prostate cancer of both neuroendocrine and adenocarcinoma origin (Supplementary Figure 2 and Figure 2). Conversely, G-G4 treatment had no effect on localised prostatic inflammation in TRAMP mice, whereas it moderately but significantly increased the incidence and distribution of PIN lesions compared with age-matched control TRAMP mice (Supplementary Figure 2 and Figure 2). A complete histopathological characterisation of Gamitrinib-treated group 2 TRAMP mice is shown in Table 2.

\section{Gamitrinib inhibits metastatic prostate cancer in TRAMP mice}

Histological analysis of untreated group 1 TRAMP mice at 24.9 weeks of age revealed the presence of large neuroendocrine tumours in the dorso-lateral and ventral prostate, and well-differentiated adenocarcinomas in various prostatic lobes
(Table 3). In all, 6 out of 10 of these animals also presented moderate prostate cancer dissemination to liver and loco-regional abdominal lymph nodes (Table 3 and Figure 2), consistent with previous observations (Hsieh et al, 2007). In contrast, none of the age-matched G-G4-treated animals in group 1 ( 0 out of 4 mice) had metastatic prostate cancer in liver or abdominal lymph nodes (Figure 2). Histological examination of brain, kidneys or lungs in these mice was also negative (not shown).

\section{Safety of long-term Gamitrinib treatment in TRAMP mice}

Both groups of TRAMP mice given Gamitrinib exhibited no significant weight loss throughout treatment (Supplementary Figure 3A). Similarly, organs harvested at the end of treatment from group 2 TRAMP mice were histologically unremarkable (Supplementary Figure 3B) compared with age-matched untreated mice (not shown).

\section{'Mitochondriotoxic' activity of Gamitrinib}

To begin elucidating the mechanism of anti-cancer activity of Gamitrinib in the TRAMP model, we next used RM1 cells that are derived from TRAMP tumours (Voeks et al, 2002). Treatment 

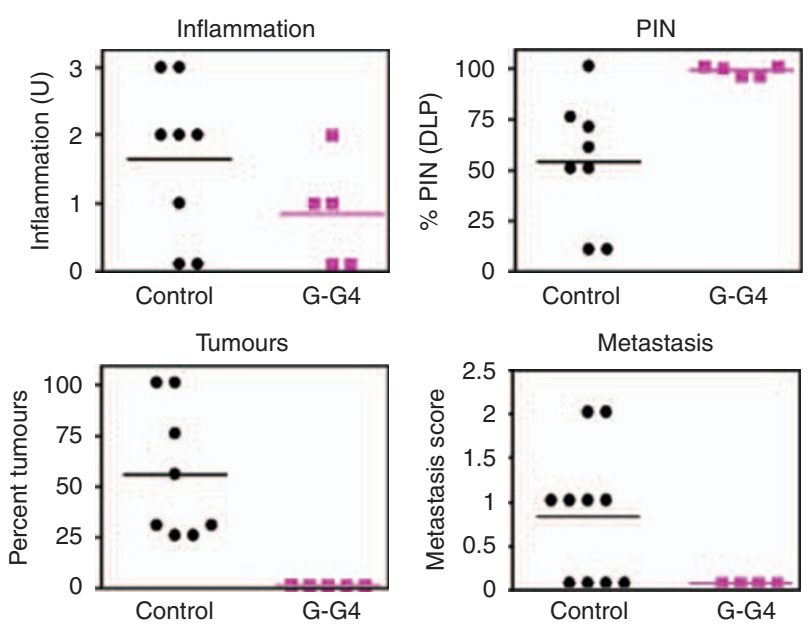

Figure 2 Quantification of prostatic lesions in untreated or Gamitrinib-treated TRAMP mice. Prostatic samples were harvested from untreated (control) or Gamitrinib (G-G4)-treated TRAMP mice, and analysed by $H \& E$ staining and light microscopy. The percentage of PIN lesions in representative matched samples of dorso-lateral prostate (DLP) from the various groups is shown. An inflammation or metastasis score was determined, and expressed as arbitrary units $(\cup)$. Quantification of inflammation (NS), PIN ( $P=0.09$ I) or tumour formation $(P=0.0038)$ was carried out in TRAMP mice at 19.7 weeks of age (group 2) Quantification of metastasis to liver and loco-regional abdominal lymph nodes was determined in TRAMP mice at 24.9 weeks of age (group I) Abbreviation: $\mathrm{NS}=$ not significant.

Table 2 Prostate histopathology of Gamitrinib-G4-treated TRAMP mice (group 2; 19.7 weeks)

\begin{tabular}{|c|c|c|c|c|}
\hline $\begin{array}{l}\text { Mouse } \\
\text { no. }\end{array}$ & $\begin{array}{c}\text { Neuro- } \\
\text { endocrine } \\
(\%)\end{array}$ & $\begin{array}{c}\text { Adeno- } \\
\text { carcinoma } \\
(\%)\end{array}$ & $\begin{array}{l}\text { PIN } \\
\text { (\%) }\end{array}$ & $\begin{array}{l}\text { Inflammation } \\
\text { (Score) }\end{array}$ \\
\hline 2999 & 0 & I (DLP) & 99 (DLP); 20 (VP); 10 (AP) & $+\mathrm{I}(\mathrm{VP})$ \\
\hline 4255 & 0 & 0 & 95 (DLP); 95 (VP); 10 (AP) & $+2(\mathrm{VP})$ \\
\hline 4260 & 0 & 0 & 100 (DLP); 50 (VP) & $+I(V P)$ \\
\hline 4464 & 0 & 0 & 95 (DLP); 95 (VP); 25 (AP) & 0 \\
\hline 4473 & 0 & 0 & 100 (DLP); 50 (VP); 10 (AP) & 0 \\
\hline
\end{tabular}

Abbreviations: $\mathrm{AP}=$ anterior prostate; $\mathrm{DLP}=$ dorso-lateral prostate; Gamitrinib $=$ GA mitochondrial matrix inhibitor; $P I N=$ prostatic intraepithelial neoplasia; TRAMP = Transgenic Adenocarcinoma of the Mouse Prostate; VP = ventral prostate

Table 3 Prostate histopathology of untreated TRAMP mice age matched to group I (24.9 weeks)

\begin{tabular}{cccc}
\hline Mouse & $\begin{array}{c}\text { Neuro- } \\
\text { endocrine (\%) }\end{array}$ & Adenocarcinoma & Metastasis \\
\hline 1207 & 0 & Well differentiated (DLP) & 0 \\
1377 & 0 & Well differentiated (DLP, AP) & + (Liver) \\
1271 & 0 & Well differentiated (DLP, AP) & + (Liver) \\
1282 & 100 (DLP, VP) & Well differentiated (AP) & + (Liver, lymph nodes) \\
1295 & 100 (DLP, VP) & 0 & + (Lymph nodes) \\
1299 & 100 & 0 & + (Liver, lymph nodes) \\
1300 & 0 & Well differentiated (DLP) & + (Liver) \\
1265 & 0 & Well differentiated (DLP) & 0 \\
1381 & 0 & Well differentiated (AP) & 0 \\
1281 & 0 & Well differentiated (DLP, AP) & 0 \\
\hline
\end{tabular}

Abbreviations: $\mathrm{AP}=$ anterior prostate; $\mathrm{DLP}=$ dorso-lateral prostate; $\mathrm{TRAMP}=$ Transgenic Adenocarcinoma of the Mouse Prostate; VP = ventral prostate.

of RM1 cells with Gamitrinib caused nearly complete loss of mitochondrial inner membrane potential, as detected by multiparametric flow cytometry (Figure $3 \mathrm{~A}$ ). This was associated with concentration-dependent release of mitochondrial cytochrome- $c$ in the cytosol of Gamitrinib-treated RM1 cells (Figure 3B). Conversely, non-subcellularly targeted 17-AAG had no effect on mitochondrial membrane potential or cytochrome- $c$ release (Figures $3 \mathrm{~A}$ and $\mathrm{B}$ ).

\section{DISCUSSION}

In this study, we have shown that systemic administration of Gamitrinib (Kang et al, 2009), a novel small molecule that targets exclusively the pool of Hsp90 in mitochondria (Kang et al, 2007), suppressed localised and metastatic prostate cancer growth in TRAMP mice (Greenberg et al, 1995), with no effect on PIN or local inflammation. Long-term systemic treatment of TRAMP mice with Gamitrinib was feasible, with no evidence of systemic or organ toxicity. Mechanistically, Gamitrinib functioned as a 'mitochondriotoxic' agent in the TRAMP model, triggering loss of organelle inner membrane potential and discharge of cytochrome- $c$ in the cytosol.

Although still the backbone of cancer drug discovery, xenograft studies in immunocompromised mice have significant drawbacks (Kelland, 2004), as tumour growth in these settings does not recapitulate the complexity of clonal selection, cross-talk with the microenvironment, interplay of inflammatory responses and acquisition of metastatic traits. This has prompted renewed interest in exploiting genetically engineered mouse models for cancer drug discovery (Walrath et al, 2010), especially for prostate cancer, where cross-talk between the tumour cell population and its microenvironment has a critical role in progression to castration resistance and metastasis (Taichman et al, 2007). Despite its well-known limitations (Pienta et al, 2008), including the preponderance of neuroendocrine tumours compared with adenocarcinoma (Chiaverotti et al, 2008), and the failure to metastasise to bones (Hsieh et al, 2007), prostatic tumourigenesis in TRAMP mice (Shappell et al, 2004) has provided a reliable genetic model for the human disease (Kaplan-Lefko et al, 2003), suitable for pre-clinical studies (Zorn et al, 2007).

Here, the anti-cancer activity of Gamitrinib in TRAMP mice extends recent studies in xenograft models (Kang et al, 2009), including prostate cancer, where systemic administration of Gamitrinib-TPP (Kang et al, 2009) suppressed the growth of subcutaneous or bone-localised PC3 prostate tumours in immunocompromised mice (Kang et al, 2010). In the TRAMP model, Gamitrinib-G4, which contains a structurally distinct mitochondrial-targeting moiety compared with Gamitrinib-TPP (Kang et al, 2009), was active across the spectrum of poorly differentiated, rapidly proliferating neuroendocrine tumours, as well as of differentiated adenocarcinoma. This is consistent with the abundant distribution of one of the targets of Gamitrinibs (Kang et al, 2007), the mitochondrial Hsp90 homologue TNF receptorassociated protein-1 (Trepel et al, 2010), in all Gleason grade localised and metastatic prostate cancer in humans, but not benign prostatic hyperplasia (Leav et al, 2010).

Consistent with earlier observations (Kang et al, 2009), the mechanism of action of Gamitrinib in the TRAMP model involved acute induction of mitochondrial dysfunction (Kang et al, 2010), with loss of organelle inner membrane potential and release of cytochrome- $c$ in the cytosol (Green and Kroemer, 2004). This produces direct tumour cell killing by Gamitrinib, at variance with the mainly cytostatic activity of non-subcellularly targeted Hsp90 inhibitors (Kang et al, 2009). In prostate cancer, Gamitrinibmediated killing indistinguishably affected androgen-dependent and -independent cell types (Kang et al, 2010; Leav et al, 2010), which may contribute to its activity against TRAMP tumours, often characterised by loss of androgen receptor (Huss et al, 2007) and androgen insensitivity (Kaplan-Lefko et al, 2003). With respect to the anti-metastatic activity of Gamitrinib in the TRAMP model, 

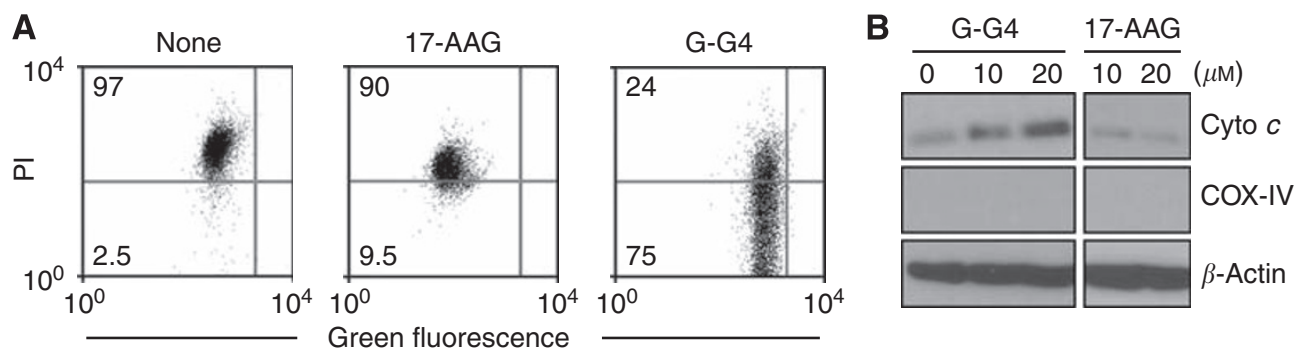

Figure 3 'Mitochondriotoxic' activity of Gamitrinib. (A) The TRAMP tumour-derived RMI cells were labelled with the mitochondrial membrane potential-sensitive dye, $\mathrm{JCl}$, incubated as indicated and analysed after $12 \mathrm{~h}$ by multiparametric flow cytometry. The percentage of cells in each quadrant is indicated. (B) RMI cells were treated as indicated, and isolated cytosolic extracts were analysed by western blotting. COX-IV and $\beta$-actin were used as mitochondrial or cytosolic markers, respectively. Abbreviations: Cyto-c = cytochrome-c; PI = propidium iodide.

it is possible that prostate cancer cells in the hypoxic environment of a metastatic niche, enriched in reactive oxygen species (Sung et al, 2008), may become especially 'addicted' to cytoprotection by mitochondrial Hsp90s (Kang et al, 2007). This model is consistent with an important role of CypD (Baines et al, 2005; Nakagawa et al, 2005) in mediating oxidative stress-induced mitochondrial permeability transition (Hua et al, 2007; Montesano Gesualdi et al, 2007), a cell death response antagonised by mitochondrial Hsp90s (Kang et al, 2007).

Long-term, continuous Gamitrinib treatment of TRAMP mice was feasible, devoid of systemic or organ side effects, in vivo. This tolerability likely reflects the low to undetectable expression of the targets of Gamitrinib, that is, mitochondrial Hsp90s, in most normal tissues, as opposed to tumours (Kang et al, 2007). This cytoprotective pathway may be also uniquely 'wired' in tumour cells, as suggested by the insensitivity of normal prostatic epithelium to Gamitrinib-mediated killing (Leav et al, 2010) and the lack of association between Hsp90s and CypD in mitochondria of normal tissues (Ghosh et al, 2010).

In sum, we have shown that one of the Gamitrinib variants, G-G4 (Kang et al, 2009), has activity in a pre-clinical genetic model of localised and metastatic prostate cancer in an

\section{REFERENCES}

Baines CP, Kaiser RA, Purcell NH, Blair NS, Osinska H, Hambleton MA, Brunskill EW, Sayen MR, Gottlieb RA, Dorn GW, Robbins J, Molkentin JD (2005) Loss of cyclophilin D reveals a critical role for mitochondrial permeability transition in cell death. Nature 434: 658-662

Butcher EC (2005) Can cell systems biology rescue drug discovery? Nat Rev Drug Discov 4: 461 - 467

Carter HB, Ferrucci L, Kettermann A, Landis P, Wright EJ, Epstein JI, Trock BJ, Metter EJ (2006) Detection of life-threatening prostate cancer with prostate-specific antigen velocity during a window of curability. J Natl Cancer Inst 98: 1521 - 1527

Chiaverotti T, Couto SS, Donjacour A, Mao J-H, Nagase H, Cardiff RD, Cunha GR, Balmain A (2008) Dissociation of epithelial and neuroendocrine carcinoma lineages in the transgenic adenocarcinoma of mouse prostate model of prostate cancer. Am J Pathol 172: 236-246

Drysdale MJ, Brough PA (2008) Medicinal chemistry of Hsp90 inhibitors. Curr Top Med Chem 8: 859-868

Ghosh JC, Siegelin MD, Dohi T, Altieri DC (2010) Heat shock protein 60 regulation of the mitochondrial permeability transition pore in tumor cells. Cancer Res 70: $8988-8993$

Green DR, Kroemer G (2004) The pathophysiology of mitochondrial cell death. Science 305: 626-629

Greenberg NM, DeMayo F, Finegold MJ, Medina D, Tilley WD, Aspinall JO, Cunha GR, Donjacour AA, Matusik RJ, Rosen JM (1995) Prostate cancer in a transgenic mouse. Proc Natl Acad Sci USA 92: 3439-3443

Heath EI, Hillman DW, Vaishampayan U, Sheng S, Sarkar F, Harper F, Gaskins M, Pitot HC, Tan W, Ivy SP, Pili R, Carducci MA, Erlichman C, immunocompetent background (Greenberg et al, 1995). Although additional work is required to define the drug-like properties of Gamitrinibs in anticipation of human testing, the data presented here suggest that selective suppression of mitochondrial Hsp90s may provide novel molecular therapy in prostate cancer, and improve the currently limited activity of Hsp90-based therapy in these patients (Trepel et al, 2010).

\section{ACKNOWLEDGEMENTS}

We thank Dr Christopher H Sotak (Worcester Polytechnic Institute) for MRI analysis. This work was supported by National Institutes of Health grants CA140043 (DCA, C-C H, LRL, JBL and GSS), CA78810, HL54131 and CA118005 (DCA).

\section{Conflict of interest}

The authors declare no conflict of interest.

Supplementary Information accompanies the paper on British Journal of Cancer website (http://www.nature.com/bjc)
Liu G (2008) A phase II trial of 17-allylamino-17-demethoxygeldanamycin in patients with hormone-refractory metastatic prostate cancer. Clin Cancer Res 14: 7940 - 7946

Hsieh CL, Xie Z, Yu J, Martin WD, Datta MW, Wu GJ, Chung LW (2007) Non-invasive bioluminescent detection of prostate cancer growth and metastasis in a bigenic transgenic mouse model. The Prostate 67: 685-691

Hua G, Zhang Q, Fan Z (2007) Heat shock protein 75 (TRAP1) antagonizes reactive oxygen species generation and protects cells from granzyme M-mediated apoptosis. J Biol Chem 282: 20553-20560

Huss WJ, Gray DR, Tavakoli K, Marmillion ME, Durham LE, Johnson MA, Greenberg NM, Smith GJ (2007) Origin of androgen-insensitive poorly differentiated tumors in the transgenic adenocarcinoma of mouse prostate model. Neoplasia 9: 938-950

Kang BH, Plescia J, Dohi T, Rosa J, Doxsey SJ, Altieri DC (2007) Regulation of tumor cell mitochondrial homeostasis by an organelle-specific Hsp90 chaperone network. Cell 131: 257-270

Kang BH, Plescia J, Song HY, Meli M, Colombo G, Beebe K, Scroggins B, Neckers L, Altieri DC (2009) Combinatorial drug design targeting multiple cancer signaling networks controlled by mitochondrial Hsp90. J Clin Invest 119: 454-464

Kang BH, Siegelin MD, Plescia J, Raskett CM, Garlick DS, Dohi T, Lian JB, Stein GS, Languino LR, Altieri DC (2010) Preclinical characterization of mitochondria-directed, small molecule Hsp90 inhibitors, Gamitrinibs, in advanced prostate cancer. Clin Cancer Res 16: 4779-4788

Kaplan-Lefko PJ, Chen TM, Ittmann MM, Barrios RJ, Ayala GE, Huss WJ, Maddison LA, Foster BA, Greenberg NM (2003) Pathobiology of 
autochthonous prostate cancer in a pre-clinical transgenic mouse model. Prostate 55: $219-237$

Kelland LR (2004) Of mice and men: values and liabilities of the athymic nude mouse model in anticancer drug development. Eur J Cancer 40: $827-836$

Kim YS, Alarcon SV, Lee S, Lee MJ, Giaccone G, Neckers L, Trepel JB (2009) Update on Hsp90 inhibitors in clinical trial. Curr Top Med Chem 9: 1479 - 1492

Lamb J, Crawford ED, Peck D, Modell JW, Blat IC, Wrobel MJ, Lerner J, Brunet JP, Subramanian A, Ross KN, Reich M, Hieronymus H, Wei G, Armstrong SA, Haggarty SJ, Clemons PA, Wei R, Carr SA, Lander ES, Golub TR (2006) The connectivity map: using gene-expression signatures to connect small molecules, genes, and disease. Science 313: 1929-1935

Leav I, Plescia J, Goel HL, Li J, Jiang Z, Cohen RJ, Languino LR, Altieri DC (2010) Cytoprotective mitochondrial chaperone TRAP-1 as a novel molecular target in localized and metastatic prostate cancer. Am J Pathol 176: $393-401$

Modi S, Stopeck AT, Gordon MS, Mendelson D, Solit DB, Bagatell R, Ma W, Wheler J, Rosen N, Norton L, Cropp GF, Johnson RG, Hannah AL, Hudis CA (2007) Combination of trastuzumab and tanespimycin (17-AAG, KOS-953) is safe and active in trastuzumab-refractory HER-2 overexpressing breast cancer: a phase i dose-escalation study. J Clin Oncol 25: $5410-5417$

Montesano Gesualdi N, Chirico G, Pirozzi G, Costantino E, Landriscina M, Esposito F (2007) Tumor necrosis factor-associated protein 1 (TRAP-1) protects cells from oxidative stress and apoptosis. Stress 10: $342-350$

Nakagawa T, Shimizu S, Watanabe T, Yamaguchi O, Otsu K, Yamagata H, Inohara H, Kubo T, Tsujimoto Y (2005) Cyclophilin D-dependent mitochondrial permeability transition regulates some necrotic but not apoptotic cell death. Nature 434: 652-658

Pienta KJ, Abate-Shen C, Agus DB, Attar RM, Chung LW, Greenberg NM, Hahn WC, Isaacs JT, Navone NM, Peehl DM, Simons JW, Solit DB, Soule HR, VanDyke TA, Weber MJ, Wu L, Vessella RL (2008) The current state of preclinical prostate cancer animal models. Prostate 68: 629-639

Shappell SB, Thomas GV, Roberts RL, Herbert R, Ittmann MM, Rubin MA, Humphrey PA, Sundberg JP, Rozengurt N, Barrios R, Ward JM, Cardiff RD (2004) Prostrate pathology of genetically engineered mice: definitions and classification. The consensus report from the Bar Harbor meeting of the Mouse Models of Human Cancer Consortium Prostate Pathology Committee. Cancer Res 64: 2270-2305
Solit DB, Osman I, Polsky D, Panageas KS, Daud A, Goydos JS, Teitcher J, Wolchok JD, Germino FJ, Krown SE, Coit D, Rosen N, Chapman PB (2008) Phase II trial of 17-allylamino-17-demethoxygeldanamycin in patients with metastatic melanoma. Clin Cancer Res 14: 8302-8307

Sung S-Y, Hsieh C-L, Law A, Zhau HE, Pathak S, Multani AS, Lim S, Coleman IM, Wu L-C, Figg WD, Dahut WL, Nelson P, Lee JK, Amin MB, Lyles R, Johnstone PAJ, Marshall FF, Chung LWK (2008) Coevolution of prostate cancer and bone stroma in three-dimensional coculture: implications for cancer growth and metastasis. Cancer Res 68: $9996-10003$

Taichman RS, Loberg RD, Mehra R, Pienta KJ (2007) The evolving biology and treatment of prostate cancer. J Clin Invest 117: 2351-2361

Taylor BS, Schultz N, Hieronymus H, Gopalan A, Xiao Y, Carver BS, Arora VK, Kaushik P, Cerami E, Reva B, Antipin Y, Mitsiades N, Landers T, Dolgalev I, Major JE, Wilson M, Socci ND, Lash AE, Heguy A, Eastham JA, Scher HI, Reuter VE, Scardino PT, Sander C, Sawyers CL, Gerald WL (2010) Integrative genomic profiling of human prostate cancer. Cancer Cell 18: 11-22

Trepel J, Mollapour M, Giaccone G, Neckers L (2010) Targeting the dynamic HSP90 complex in cancer. Nat Rev Cancer 10: 537-549

Tse AN, Klimstra DS, Gonen M, Shah M, Sheikh T, Sikorski R, Carvajal R, Mui J, Tipian C, O'Reilly E, Chung K, Maki R, Lefkowitz R, Brown K, Manova-Todorova K, Wu N, Egorin MJ, Kelsen D, Schwartz GK (2008) A phase 1 dose-escalation study of irinotecan in combination with 17-allylamino-17-demethoxygeldanamycin in patients with solid tumors. Clin Cancer Res 14: 6704-6711

Voeks DJ, Martiniello-Wilks R, Russell PJ (2002) Derivation of MPR and TRAMP models of prostate cancer and prostate cancer metastasis for evaluation of therapeutic strategies. Urol Oncol 7: 111-118

Vogiatzi P, Cassone M, Claudio L, Claudio PP (2009) Targeted therapy for advanced prostate cancer: looking through new lenses. Drug News Perspect 22: 593-601

Walrath JC, Hawes JJ, Van Dyke T, Reilly KM (2010) Genetically engineered mouse models in cancer research. Adv Cancer Res 106: 113-164

Whitesell L, Lindquist SL (2005) HSP90 and the chaperoning of cancer. Nat Rev Cancer 5: $761-772$

Zorn CS, Wojno KJ, McCabe MT, Kuefer R, Gschwend JE, Day ML (2007) 5 -aza-2'-deoxycytidine delays androgen-independent disease and improves model of prostate survival in the transgenic adenocarcinoma of the mouse prostate mouse cancer. Clin Cancer Res 13: 2136-2143 